\title{
Significant differences in alkaloid content of Coptis chinensis (Huanglian), from its related American species Shreya Kamath ${ }^{1}$, Matthew Skeels ${ }^{1}$ and Aswini Pai*2
}

Address: ${ }^{1}$ Department of Chemistry, St Lawrence University, Canton, New York 13617, USA and ${ }^{2}$ Department of Biology, St Lawrence University, Canton, New York 13617, USA

Email: Shreya Kamath - sakama04@stlawu.edu; Matthew Skeels - mskeels@stlawu.edu; Aswini Pai* - apai@stlawu.edu

* Corresponding author

Published: 24 August 2009

Chinese Medicine 2009, 4:17 doi:10.1/86/1749-8546-4-17

This article is available from: http://www.cmjournal.org/content/4/I/I7

(c) 2009 Kamath et al; licensee BioMed Central Ltd.

This is an Open Access article distributed under the terms of the Creative Commons Attribution License (http://creativecommons.org/licenses/by/2.0), which permits unrestricted use, distribution, and reproduction in any medium, provided the original work is properly cited.
Received: 13 January 2009

Accepted: 24 August 2009

\begin{abstract}
Background: The growing popularity of Chinese herbal medicine in the United States has prompted large-scale import of raw herbs from Asia. Many of the Asian herbs have phylogenetically related North American species. We compared three phylogenetically related species, namely Coptis chinensis (Huanglian), Hydrastis canadensis and Coptis trifolia to show whether they can be substituted by one another in terms of alkaloid content.
\end{abstract}

Methods: We used microwave assisted extraction to obtain alkaloids berberine, coptisine, palmatine and hydrastine. High performance liquid chromatography (HPLC) was used to quantify each alkaloid.

Results: Hydrastis canadensis has the most berberine, whereas Coptis trifolia has the most coptisine. Hydrastine and palmatine were unique to Hydrastis canadensis and Coptis chinensis respectively.

Conclusion: Neither Hydrastis canadensis nor Coptis trifolia contains all the alkaloids found in Coptis chinensis used in Chinese medicine. Substitutes of this Chinese species by its American relatives are not recommended.

\section{Background}

Phylogenetically related plant species exhibit phytochemical similarities [1]. For example, taxol is an anti-cancer chemical compound initially isolated from the bark of a rare tree species Taxus brevifolia (Pacific Yew tree); however, a closely related and more available species, Taxus cuspidata was later proved to be a more commercially viable source for taxol [2]. The growing popularity of Chinese herbal medicine in the United States has prompted largescale import of raw herbs from Asia [3]. As many Chinese medicinal plants are evolutionarily related to their North American congeners, the North American species may be possible phytochemical substitutes to the Chinese medic- inal herbs [4]. For example, North American ginseng (Panax quinquifolium) has become the commercial alternative to the rarer Chinese ginseng (Panax ginseng) [5]. Growing native substitutes can potentially promote local industry and reduce the ecological risks of cultivating exotic species; however, there is little information available on possible North American phytochemical substitutes to Chinese medicinal herbs.

The present study investigates the alkaloid content in Coptis trifolia (American goldthread) and Hydrastis canadensis (goldenseal), two herbs found in the United States, and Coptis chinensis (Huanglian, Chinese goldthread), a Chi- 
nese medicinal herb imported from China. The three species belong to the same Ranunculaceae family and have alkaloid rich rhizomes. Phylogenetically related to Hydrastis canadensis, the genus Coptis has several North American and Asian species [6].

During the $18^{\text {th }}$ century, Native Americans used the rhizome of Coptis trifolia to treat mouth sores, poor digestion and infections. The species had become scarce due to over harvesting and/or loss of habitat caused by human activities. It was substituted with Hydrastis canadensis, which remains available commercially to this date despite the fact that the growth of Coptis trifolia has recovered in the northeastern United States [7]. Hydrastis canadensis is an 'at risk' species due to the potential for over harvest but can be cultivated on a small scale [8]. Both species are phylogenetically related to Coptis chinensis which is used to treat digestive and respiratory disorders in Chinese medicine [9].

A review of available literature indicates that there has been considerably more pharmacological research on Coptis chinensis than Hydrastis canadensis and Coptis trifolia. Current findings show some of their similarities. Bioassays on Coptis chinensis and Hydrastis canadensis indicate that both herbs possess anti-microbial activities [10,11]. In addition, Coptis chinensis is anti-inflammatory [12] and Hydrastis canadensis may improve immune function [13]. Pharmacological studies on Coptis trifolia are still lacking. Coptis chinensis contains alkaloids such as berberine, palmatine, epiberberine, coptisine, jaterorhizine and columbamine. Hydrastis canadensis also contains alkaloids such as berberine, hydrastine, hydrastinine and canadine $[4,14]$. Isoquiniline alkaloids in Coptis trifolia were suggested to be similar to those in Coptis chinensis yet they have not been fully characterized [3]. Berberine, a benzylisoquinoline alkaloid, has been found in all three species and has been demonstrated to be anti-carcinogenic and anti-microbial [15].

The present study aims to investigate whether berberine, coptisine, hydrastine and palmatine (major isoquinoline alkaloids) are quantitatively comparable in content among rhizomes of Hydrastis canadensis, Coptis trifolia and Coptis chinensis.

\section{Methods}

Hydrastis canadensis $(n=20)$ was obtained from Horizon Herbs, Oregon, USA. Coptis trifolia $(n=20)$ was harvested from the Wachmeister field station northern New York, USA. Coptis chinensis rhizomes $(n=20)$ were obtained from a supplier in Montreal, Canada. The whole plants of Hydrastis canadensis and Coptis trifolia were authenticated by comparing their morphology with type specimens at the St Lawrence University herbarium [16]. The Coptis chinensis rhizomes were authenticated by comparing the high performance liquid chromatography (HPLC) peaks to those from published data $[17,18]$.

Acetonitrile and methanol (HPLC-grade) were obtained from Pharmco-AAPER (USA). Hexane and phosphoric acid (ACS grade) were obtained from JT Baker (USA). Berberine, palmatine and coptisine were obtained from Sigma-Aldrich (USA) and hydrastine was purchased from MP Biomedical (USA).

All rhizomes of the three herbs were dried at $75^{\circ} \mathrm{C}$ in a forced air oven for 72 hours and subsequently were ground into fine powder with a mortar and pestle. Alkaloids were extracted with a microwave assisted extraction (MAE) technique [19] and quantified with HPLC [20]. Samples were soaked in $30 \mathrm{~mL}$ of extraction solvent. Solvents described by Anderson et al. [21] and Li et al. [22] were used. Specifically, an extraction solvent of 50:50:0.1 $(\mathrm{v} / \mathrm{v})$ hexane-ethanol-phosphoric acid mixture was used for Hydrastis canadensis while a 100:0.1 (v/v) methanolphosphoric acid was used for Coptis trifolia and Coptis chinensis. These acidified polar solvents effectively extract the isoquinoline alkaloids in their highly soluble, protonated forms. We carried out the method of Li et al. [22], except that MAE was employed to shorten the overnight extraction time. The samples were placed in a Aurora MW500 microwave (Aurora Instruments, Canada) programmed to ramp temperature from $25^{\circ} \mathrm{C}$ to $120^{\circ} \mathrm{C}$ in four minutes, followed by 90 minutes of extraction at $120^{\circ} \mathrm{C}$. Filtered extracts were dried in a Heidolph roto-vaporizer (Heidolph Elektro, Germany) under vacuum of $367 \mathrm{mbar}$ at $70^{\circ} \mathrm{C}$ and $150 \mathrm{rpm}$. The dried residue was dissolved in a minimal volume of $100 \%$ HPLC-grade acetonitrile, ranging from $400 \mu \mathrm{l}$ to $2 \mathrm{~mL}$ (depending on the residue quantity) for 24 hours.

HPLC analyses were performed according to the validated method of Weber et al. [20] on a ThermoSeparations SpectraSYSTEM (Thermo Scientific, USA) chromatograph with an Agilent Eclipse XDB-C18 (4.6 mm $\times 250 \mathrm{~mm} \times 5 \mu \mathrm{m})$ column (Agilent Technologies, USA). The flow rate of the mobile phase, which consisted of $0.2 \mathrm{M}$ ammonium acetate ( $\mathrm{pH} 4.85)$ and acetonitrile (69:31, v/v), was maintained at $1.0 \mathrm{~mL}$ per minute [20] and absorbance was measured at $235 \mathrm{~nm}$ and $266 \mathrm{~nm}$. Alkaloids in each sample were identified according to their standard retention times and characteristic $\mathrm{A}_{235} / \mathrm{A}_{266}$ ratios. To corroborate alkaloid identity in samples, we used 'spiking tests' with known standards. Peak area at 266 nm was used to quantify alkaloid content.

Stock solutions were prepared by weighing $5 \mathrm{mg}$ of standard with a Cahn C-35 microbalance (Themo Scientific, USA) into individual $10 \mathrm{~mL}$ volumetric flasks and diluting 
it to volume with water and acetonitrile $(10: 90 \mathrm{v} / \mathrm{v})$. A 5 $\mathrm{mL}$ aliquot of each stock solution was transferred into a $25 \mathrm{~mL}$ volumetric flask and diluted to volume with water and acetonitrile $(70: 30, \mathrm{v} / \mathrm{v})$. Wrapped in aluminum foil and refrigerated, the stock solutions were stable for over two months. Various volumes of standards were analyzed in triplicates to produce standard curves ( 0.5 to $2 \mu \mathrm{g}$ ). Individual calibration curves, plotted for each alkaloid, were linear $\left(R^{2}>0.99\right)$ over the range of interest.

As the data did not meet the assumption of equal variance, we used non-parametric tests instead of parametric tests for statistical analyses. Kruskal-Wallis test was used to compare Berberine content was compared amongbetween Hydrastis canadensis, Coptis trifolia and Coptis chinensis, whereas Mann-Whitney U test was used to compare coptisine content between Coptis trifolia and Coptis chinensis.

\section{Results and discussion}

Figure 1 shows the representative chromatograms of the three herbs. Berberine was quantified in all three species. Coptisine was quantified in Coptis chinensis and Coptis trifolia. Hydrastine and palmatine were unique to Hydrastis canadensis and Coptis chinensis respectively but absent in Coptis trifolia. The Kruskal-Wallis test indicates a significant difference $(\mathrm{H}=49.67, P<0.0001)$ in berberine content among the three species. Hydrastis canadensis has the greatest berberine content, followed by Coptis chinensis and Coptis trifolia (Table 1). The Mann-Whitney U test indicates a significant difference $(Z=3.45, P<0.0001)$ in the coptisine content in the rhizomes of Coptis trifolia and Coptis chinensis. Coptis trifolia has higher mean coptisine content than that of Coptis chinensis.

These results show that Hydrastis canadensis is the best source for berberine, whereas Coptis trifolia is the best source for coptisine. Neither of the two North American species has all the alkaloids found in their Chinese congener Coptis chinensis. Hydrastis canadensis and Coptis trifolia together contain all the alkaloids found in Coptis chinensis except palmatine. Therefore, a combined formulation of the two North American herbs may provide most of the alkaloids in Coptis chinensis and may be acceptable to the North American dietary supplements industry if only a few key phytochemicals are required [23]. As growth conditions can influence alkaloid content of a plant, further investigation is indeed needed on how cultivation of the American species may make the substitution possible.

If there is any difference in photochemical content, possible interactions [24], toxicity of the active constituents and the phytochemicals introduced from the American species should be studied. Otherwise, substitution of the Chinese species by the American ones is not recommended.
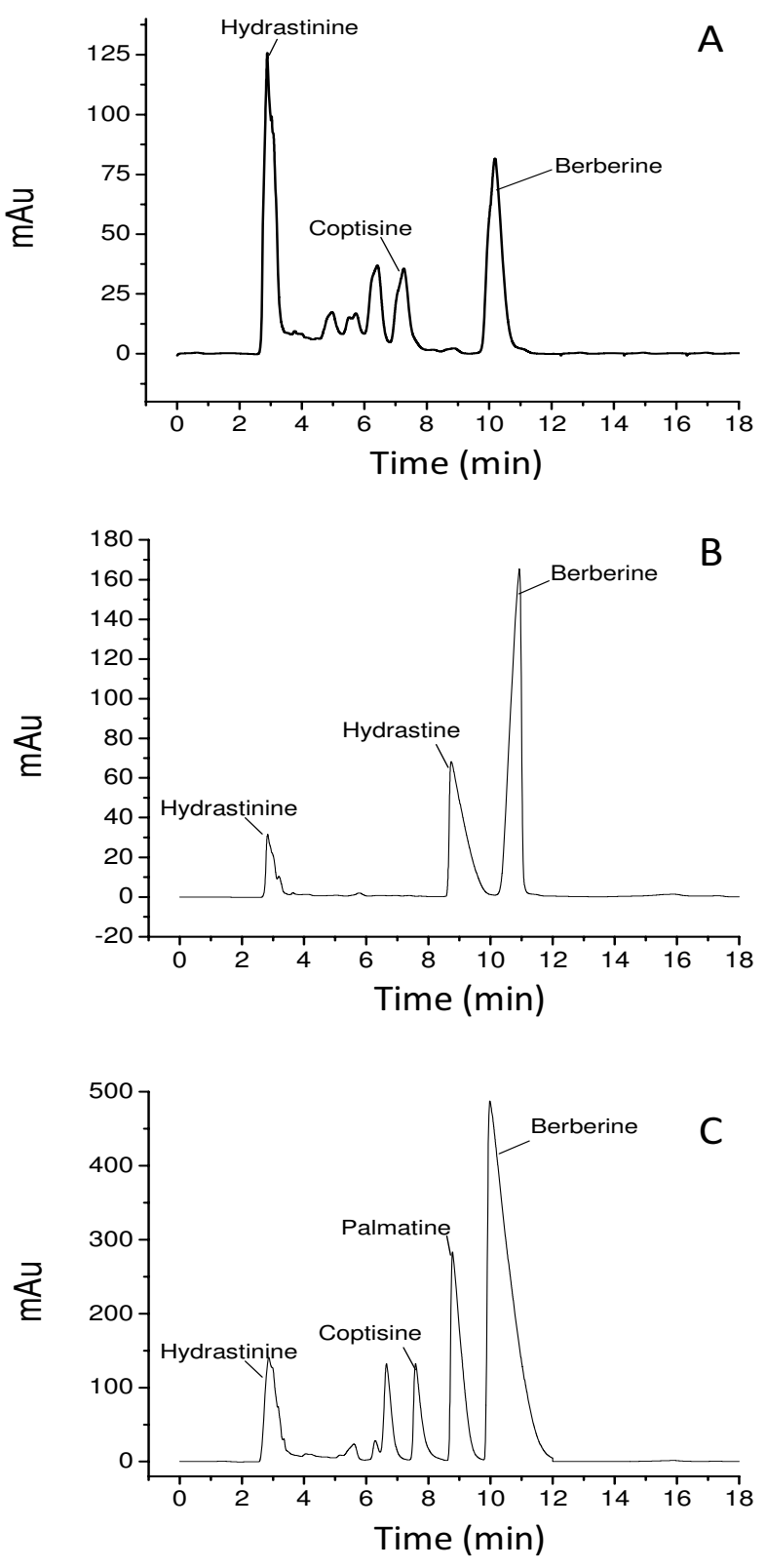

Figure I

Representative HPLC chromatograms. (A) Coptis trifolia. (B) Hydrastis canadensis. (C) Coptis chinenesis. All three herbs contain hydrastinine and berberine. Coptisine is present in Coptis trifolia and Coptis chinenesis. Palmatine is only detected in Coptis chinensis, whereas hydrastine is only present in Hydrastis canadensis.

\section{Conclusion}

Neither Hydrastis canadensis nor Coptis trifolia contains all the alkaloids found in Coptis chinensis used in Chinese medicine. Substitutes of this Chinese species by its American relatives are not recommended. 
Table I: Alkaloid content in rhizomes $(n=20)$ of Hydrastis canadensis, Coptis chinensis and Coptis trifolia (Similar alkaloids differ significantly among species at $P<0.0001$.)

\begin{tabular}{lcc}
\hline Species & Major alkaloids & Mean (SD) alkaloid content (mg/g of rhizome) \\
\hline Hydrastis canadensis & Berberine & $16.76(3.42)$ \\
& Hydrastine & $4.81(1.48)$ \\
Coptis chinensis & Berberine & $10.60(1.36)$ \\
& Coptisine & $2.35(0.27)$ \\
Coptis trifolia & Palmatine & $2.91(0.38)$ \\
& Berberine & $3.80(1.90)$ \\
& Coptisine & $3.44(1.45)$ \\
\hline
\end{tabular}

\section{Abbreviations}

MAE: microwave assisted extraction; HPLC: high performance liquid chromatography; SD: standard deviation

\section{Competing interests}

The authors declare that they have no competing interests.

\section{Authors' contributions}

AP conceived the study design and performed the statistical analyses. MS conceptualized and supervised the HPLC. SK performed the HPLC. All authors participated in the writing of the manuscript. All authors read and approved the final version of the manuscript.

\section{Acknowledgements}

We thank the Summer Fellows program and the Departments of Chemistry and Biology at St Lawrence University for logistical and financial support during the study.

\section{References}

I. Harborne JB, Turner BL: Plant Chemosystematics. London: Academic Press Inc; 1984

2. Fett-Neto AG, Zhang WY, Dicosmo F: Kinetics of taxol production, growth, and nutrient uptake in cell suspensions of Taxus cuspidata. Biotechnol Bioeng 1994, 44:205-210.

3. Brevoort P: The booming U.S. botanical market: a new overview. HerbalGram 1996, 44:33-46.

4. Li TSC: Chinese and Related North American Herbs: Phytopharmacology and Therapeutic Values Boca Raton: CRC Press; 2002

5. Robbins CS: Comparative analysis of management regimes and medicinal plant trade monitoring mechanisms for American Ginseng and Goldenseal. Consv Biol 2000, 14:1422-1434.

6. Jensen U, Hoot SB, Johansson JT, Kosuge K: Systematics and phylogeny of the Ranunculaceae a revised family concept on the basis of molecular data. Plant Syst Evol 1995, 9(Suppl):273-280.

7. Bergner P: Coptis: a Hydrastis Substitute. Med Herb J 1996, 8:13-14.

8. Cech R: Growing At Risk Medicinal Herbs Williams: Horizon Herbs; 2002.

9. Chen J, Chen T: Chinese Medical Herbology City of Industry: Art of Medicine Press; 2004.

10. Lin CC, $\mathrm{Ng} \mathrm{LT}$, Hsu FF, Shieh DE, Chiang LC: Cytotoxic effects of Coptis chinensis and Epimedium sagittatum extracts and their major constituents (berberine, coptisine and icariin) on hepatoma and leukaemia cell growth. Clin Exp Pharmacol Physiol 2004, 31:65-69.

11. Collins RA, Ng TB, Fong WB, Wan CC, Yeung HW: A comparison of human immunodeficiency virus type I inhibition by partially purified aqueous extracts of chinese medicinal herbs. Life Sci 1997, 60:345-35I.
12. Cuéllar MJ, Giner RM, Recio MC, Máñez S, Ríos JL: Topical antiinflammatory activity of some Asian medicinal plants used in dermatological disorders. Fitoterapia 200I, 72:22I-229.

13. Rehman J, Dillow JM, Carter SM, Chou J, Le B, Maisael AS: Increased production of antigen-specific immunoglobulins $\mathbf{G}$ and $M$ following in vivo treatment with the medicinal plants Echinacea angustifolia and Hydrastis canadensis. Immunol Lett 1999, 68:391-395.

14. Yang F, Zhang T, Zhang R, Yoichiro I: Application of analytical and preparative high-speed counter-current chromatography for separation of alkaloids from Coptis chinensis Franch. J Chromatogr 1998, 829:| 37-|4|.

15. Birdsall TC, Kelly GS: Berberine: therapeutic potential of an alkaloid found in several medicinal plants. Altern Med Rev 1997, 2:94-103.

16. Zhao Z, Xiao P, Xiao Y, Yuen JPS: Quality assurance of Chinese herbal medicines (CHMS). J Food Drug Anal 2007, 1 5:337-346.

17. Huang $X P$, Li LY, Qu XY, Cu GL: Fingerprints of rhizoma coptidis from Shizhu by HPLC. Zhongyaocai 2006, 29:666-9.

18. Lee YA, Hong SJ, Lee SH, Kim KS, Park EK, Jung K, Han CS, Yoo MC, Yang $\mathrm{HI}$ : Coptis chinensis extract inhibits the production of inflammatory mediators and delayed type hypersensitivity in mice. Immune Network 2008, 8: I3-20.

19. Mandal V, Mohan Y, Hemalatha S: Microwave assisted extraction an innovative and promising extraction tool for medicinal plant research. Pharmacog Rev 2007, I:7-17.

20. Weber HA, Zart MK, Hodges AE, Molloy HM, O'Brien BM, Moody LA, Clark AP, Harris RK, Overstreet JD, Smith CS: Chemical comparison of Goldenseal (Hydrastis canadensis L.) root powder from three commercial suppliers. J Agr Food Chem 2003, 5 I:7352-58.

21. Anderson ML, Burney DP: A validated high performance liquid chromatographic method for the analysis of goldenseal. J AOAC Intern 1998, 81: 1005-I II0.

22. Li W, Fitzloff JF: A validated high performance liquid chromatographic method for the analysis of goldenseal. J Pharm Pharmacol 2002, 54:435-439.

23. Sander LC, Sharpless KE, Wise SA: Dietary supplement standard reference materials. Life Sci 2006, 78:2044-8.

24. Patwardhan B, Warude D, Pushpangadan P, Bhatt N: Ayurveda and traditional Chinese medicine: a comparative overview. EvidBased Compl Alt 2005, 2:465-473. 